\title{
LA REFORMA DE JOSÍAS Y LA LEGITIMACIÓN DE LA VIOLENCIA
}

\author{
Consideraciones arqueológico-históricas, \\ exegéticas y hermenéuticas en la perspectiva \\ de género, a partir de $2 \operatorname{Re} 23,1-25$
}

\author{
Sue'Hellen Monteiro de Matos \\ Universidade Metodista de São Paulo \\ suehellen.matos@gmail.com \\ (iD) https://orcid.org/0000-0002-6050-488X
}

Resumen: El presente artículo tiene por objetivo discutir la violencia legitimada en la reforma de Josías, a partir de la narrativa de 2 Re 23,1-25, considerando los aspectos narrativos y arqueológico-históricos de tal hecho. A partir de ello, presenta algunas consideraciones exegéticas de los términos que expresan la violencia, así como realiza un análisis de esta violencia desde la perspectiva de género, buscando nuevos caminos hermenéuticos.

Palabras clave: Reforma de Josías. Arqueología. Violencia. Género. Hermenéutica feminista.

\section{The Josiah's Reform and Legitimation of Violence}

Archaeological-historical considerations, exegetical and hermeneutic in gender perspective from $2 \mathrm{Kgs}$ 23,1-25

Abstract: This article discusses the legitimated violence in Josiah's reform considering narrative and archeological-historical aspects, as well as exegetical consideration of the terms expressing violence of $2 \mathrm{Kgs}$ 23:1-25. An analysis of this violence from a gender perspective aimed at new hermeneutic paths completes the study. 
Keywords: Josiah's reform. Archeology. Violence. Gender. Feminist hermeneutics.

\section{Introducción}

La violencia explícita o simbólica atraviesa los textos bíblicos del Antiguo Testamento, sea en narrativas de guerra (cf. 2 S 8,1-13) y de violación (cf. Jue 19), o en códigos legislativos que, en gran parte, acaban normatizando modelos patriarcales (cf. Ex 21,7) e, inclusive, legitimando la violencia contra el prójimo a medida que la práctica de la violencia se soluciona con la pena de muerte (cf. Ex 21,12). Tenemos, también, narrativas que legitiman la violencia y la intolerancia religiosa, como la narrativa de la reforma de Josías, que será abordada en nuestro estudio.

A partir de los nuevos descubrimientos arqueológicos ${ }^{1}$ asociados con una lectura crítica de los textos bíblicos, se puede considerar que los principales momentos de redacción de los textos del Antiguo Testamento serían la época de Josías (siglo viI A. E. C.) y también el período atribuido a Esdras (siglo v A. E. C.), cuando la teocracia sacerdotal era predominante. En todos estos momentos observamos actitudes violentas, intolerantes y discriminatorias (cf. Esd 9), e incluso hasta masacres en nombre de Dios (cf. 2 Re 23,20). Tales actos, especialmente la reforma josiánica, fueron legitimados por el hallazgo del libro de la Ley (2 Re 22,8) -probablemente el material encontrado en Deuteronomio 6-26-, que tuvo su autoridad verificada por la profetisa Juldá $(2 \operatorname{Re} 22,11-20)^{2}$.

Hay muchas violencias y cambios forzados implicados en esta reforma. No solamente con las diferentes deidades presentes en el templo de Jerusalén, sino también con todos y todas los que servían a estas divinidades. Tal legitimación refuerza la intencionalidad de los historiadores deuteronomistas de fortalecer la elevación de YHWH como Dios único de Israel, $\mathrm{y}$, en consecuencia, de Israel como pueblo exclusivo de YHWH.

Así, estas narrativas resaltan la violencia generada durante el proceso de constitución del monoteísmo en Israel. Dietrich ${ }^{3}$ destaca que:

1 Cuando nos acercamos a los nuevos hallazgos arqueológicos, consideramos las discusiones de las últimas décadas sobre la cronología alta y baja, según los argumentos de Amihai Mazar e Israel Finkelstein en FINKELSTEIN - MAZAR, The Quest for the Historical Israel.

2 Dietrich, “'Palavra de Deus' e violência”, 179.

3 Ib., 188. 
Muchos de los textos que legitiman e incitan la violencia contra las otras culturas y religiones, contra personas que nombran y dan culto al Misterio de Dios de otra manera, fueron elaborados durante la reforma de Ezequías y de Josías. El problema está en que estos textos comienzan a ser instituidos como "Palabra de Dios" y consagrados dentro de estas reformas.

Bajo el argumento de "Palabra de Dios", evidenciado en la literatura deuteronomista como ley de YHWH, la violencia de género también está legitimada, tanto en relación con las deidades femeninas como en relación con sus sacerdotisas. Por eso, Dietrich apunta a la importancia de los hallazgos arqueológicos para una mejor comprensión de la historia de Israel y de la composición de los textos bíblicos para observar las ideologías imperialistas presentes en estos textos, para proponer una nueva lectura de los textos bíblicos que no legitime la violencia pautada en la "Palabra de Dios" 4

Por lo tanto, la propuesta de este artículo es presentar una discusión histórico-arqueológica de la narrativa de $2 \operatorname{Re} 23,1-25$ a partir de la cual se discutirá la violencia legitimada por la "Palabra de Dios" en esta narrativa con el fin de proponer una nueva hermenéutica en la perspectiva de género, una vez que esta narrativa de la reforma de Josías nos ofrece elementos exegéticos para analizar las diferentes formas de violencia presentes en el texto, sea con relación a las deidades presentes en el templo que no sea YHWH, así como con relación a las sacerdotisas y a los sacerdotes de las otras divinidades. Además, considerando que discutir sobre género no solo se delimita a hablar de mujer, sino también a estudiar las relaciones de poder entre los sexos, es crucial para nuestra investigación abordar las relaciones de poder que envuelven los/las personajes de la narrativa.

\section{Reforma de Josías: narrativa, arqueología e historia}

Para comprender mejor la violencia legitimada por la "Ley de YHWH" descrita en la narrativa de 2 Re 23,1-25, es necesario discutir respecto de los aspectos narrativos e históricos de la reforma de Josías.

Desde el punto de vista narrativo, el texto pertenece a la Obra Historiográfica Deuteronomista (OHD), que tiene como uno de sus principales puntos teológicos un solo lugar para adorar a YHWH, Jerusalén. La OHD no solo se limita a recopilar, ordenar y repasar hechos, sino que pretende interpretarlos. Por eso mismo, los criterios de la OHD son unilaterales. No

\footnotetext{
4 Ib., 183.
} 
se habla de transgresiones éticas o políticas, o denuncia de las injusticias sociales; por el contrario, solo se mencionan transgresiones cúlticas. Los libros de los Reyes siguen esta perspectiva. Ellos relatan los acontecimientos de los reyes, pero los interpretan a partir de su óptica de la culpa y de los juicios divinos, colocando la apostasía como factor diferencial entre un buen y un mal rey ${ }^{5}$.

Las primeras actividades literarias de los deuteronomistas, según Römer ${ }^{6}$, se dieron en la corte de Jerusalén, durante el siglo viI A. E. C., por funcionarios de la corte, posiblemente escribas. Existen diferentes formas literarias, principalmente en Deuteronomio y Josué, que se corresponden con escritos asirios y su cultura. Por ejemplo, el fortalecimiento de la ideología militarista asiria es utilizado con relación a YHWH y a su pueblo. Así pues, el propósito de estos escritos sería ofrecer soporte ideológico a la política de centralización y a la pretensión de que el reino de Judá era el "verdadero Israel". Esta ideología afectó el dominio político, económico y religioso, teniendo mayor impacto cuando, después de 722 A. E. C., Jerusalén se torna la "verdadera capital", centralizando el poder político y económico. Frente a ello, el ambiente se hizo propicio para fortalecer una ideología de centralización del culto, favorable a los deuteronomistas josiánicos, de promover una adoración monolátrica a YHWH a nivel de religión de Estado.

De esta forma, el templo de Jerusalén se convirtió en elemento fundamental para el desarrollo de esta monolatría estatal. Para los deuteronomistas, el templo de Jerusalén es el único lugar donde se debe dar culto a YHWH y debe estar libre de manifestaciones cultuales extranjeras que puedan colocar la fe yavista en riesgo ${ }^{7}$. Por esta razón, el templo de Jerusalén se convirtió en centro fundamental para las medidas reformistas.

Narrativamente, la reforma josiánica no fue la primera a realizarse. Antes, con el rey Ezequías (2 Re 18,4-6) hubo un primer movimiento para la transformación de YHWH de Dios nacional en Dios exclusivo. A tal fin, Ezequías promovió la destrucción de las bamôt; aún más: fue el primer rey a quien el deuteronomista atribuye la destrucción de los lugares altos, además de cambios en el organización del templo (no solamente ornamentación, sino también en las estructuras de las paredes) para hacerlo más apropiado a las innovaciones del culto. Sin embargo, estos cambios fueron difícilmente aceptados por la población habituada con sus cultos agrarios

5 Schmidt, Introdução ao Antigo Testamento, 141.

6 Römer, A chamada história deuteronomista, 52-53.

7 Liverani, Para além da Bíblia, 223. 
y también porque su sucesor, Manasés (687-642 A. E. C.), reintrodujo el pluralismo religioso, reedificando los lugares altos y otros símbolos de cultos de fertilidad ${ }^{8}$.

$\mathrm{Al}$ reconstruir los lugares altos e introducir el pluralismo religioso en el templo de Jerusalén, Manasés fue visto con un rey profanador, lo que lo tornó malo ante YHWH (2 Re 21,2-9). Pero, ¿sería él tan profano por incluir en el templo elementos de la religiosidad popular? ¿Habrán sido incluidos o ya estaban presentes allá antes que Manasés llegara? Probablemente siempre estuvieron presentes en el templo.

Con seguridad, el discurso ideológico deuteronomista conduce el narrativa de la historia, visto que el principio deuteronomista es la exclusividad de la fe en YHWH. La prohibición de mezclarse con las naciones extranjeras que restaban en Canaán y la prohibición de servir a otros dioses (cf. Jos 23,6-7) refuerza la exclusividad de la fe yavista. Para los deuteronomistas, cualquier deidad que no sea YHWH es extranjero/a y, por lo tanto, no debe ser adorado/a. De esta forma, el relato de la reforma josiánica, según 2 Re 23,1-25, es contumaz en el desmantelamiento de los lugares de culto no yavistas, principalmente las bamôt, tanto en la propia Jerusalén como en todo territorio de Judá, así como en Betel y Samaría.

Desde el punto de vista arqueológico, existen poquísimos indicios de la reforma de Josías. Hay intentos de probarla por la decadencia del santuario de Arad, pues allí se encontraron los altares y dos estelas derrumbados, suponiendo que habrían sido derrumbadas por el ejército de Josías. Sin embargo, hay muchas controversias sobre la datación de la construcción y la decadencia de este santuario. Por otro lado, fue construido un fuerte en Arad bajo el reinado de Manasés o de Josías, y el hecho de que el santuario no fuese restablecido en esta época es un fuerte indicio de la creciente importancia de Jerusalén, del templo y de la probable reforma josiánica9.

Sin embargo, no hay evidencias arqueológicas de la destrucción en Betel, como la relata el texto bíblico de 2 Re 23,15-20. Finkelstein y Singer-Avitz analizaron cerámicas fechadas entre los siglos vi a IV A. E. C. que fueron encontradas en Betel, concluyendo que esta evidencia material indica actividad cultual y económica durante el período babilónico, persa y helénico ${ }^{10}$. Römer argumenta que tal conclusión de los arqueólogos se combina con el hecho de que Betel es raramente mencionado en textos

8 Ib., 199-200.

9 Römer, A origem de Javé, 191.

10 Finkelstein - Singer-Avitz, Reevaluating Bethel, 33-48. 
proféticos de los períodos babilónico o persa ${ }^{11}$. Aún más, si realmente Betel hubiese sido destruida, era de esperar que los profetas judaítas celebraran tal evento. Por lo tanto, de acuerdo con el autor, es más plausible entender 2 Re 23,15-20 en el contexto de la anexión de Josías por Benjamín, que perteneció a Betel, sin la destrucción del santuario.

Por otro lado, hay indicios que comprueban la existencia de una reforma cúltica en el siglo viI A. E. C., solo que en Judá. Hay un cambio de la glíptica judaíta entre los siglos VII y vi A. E. C. En el siglo viI, los sellos de la aristocracia y de los funcionarios eran grabados con temas astrales y representaciones antropomórficas de las divinidades. Ya del inicio del siglo VI, se encontraron 260 sellos con temas abstractos. No hay más símbolo de divinidades astrales. Sin embargo, a partir del siglo vi no hay ninguna iconografía que pueda identificar la pareja YHWH y Asherá. No obstante, en la inscripción de Khikert Beit Lei se encuentra una referencia a Jerusalén, donde estaría escrito: "YHWH es el Dios de toda la tierra, Dios de Judá y de Jerusalén". Aunque sea una inscripción de difícil datación y lectura, si fuera del final del siglo vII, podría corroborar la hipótesis de una centralización del culto yavista ${ }^{12}$.

Para contribuir con la evidencia de una reforma josiánica, recientemente en la excavación en la ciudad de David, coordinada por Yuval Gadot de la Tel-Aviv University e Yiftah Shalev de la Autoridad de Antigüedades de Israel, fue encontrado un sello fechado entre mediados del siglo vII e inicio del siglo vi A. E. C., con la inscripción "[perteneciente a] Netán-Mélek, Siervo del Rey". Este nombre aparece solo una vez en la Biblia, en 2 Re 23,11 , siendo descrito como un oficial de la corte del rey Josías. Estos artefactos, destacan Gadot y Shalev, testifican el sistema altamente desarrollado de administración en el reino de Judá y añaden informaciones considerables sobre la economía de Jerusalén, así como informaciones personales sobre los oficiales más próximos del rey y administradores que vivían y trabajaban en la ciudad ${ }^{13}$.

Además, otro punto relevante para la evidencia de una reforma política y religiosa bajo el reinado de Josías proviene de los símbolos y prácticas de culto que fueron excluidos del templo de Jerusalén. De acuerdo con Römer, algunas de las acciones descritas en $2 \operatorname{Re} 23$ se refieren al culto

11 Römer, Rise and Fall of Josiah, 331.

12 Römer, A origem de Javé: o Deus de Israel e seu nome, 191-192.

13 Se puede ver un informe completo sobre el nuevo descubrimiento en ISRAEL, "Seal Bearing Name". 
astral, que era una parte importante de la ideología religiosa neoasiria ${ }^{14}$. Por ejemplo, la referencia a los caballos y carruajes de Shamash (v. 11) es históricamente plausible en el contexto de una influencia asiria en el culto en Judá. Además, la clase sacerdotal $k^{e} m \bar{a} r i ̂ m$, relatada en la narrativa, sería un grupo de sacerdotes vinculado al culto de las divinidades astrales; ellos eran tal vez una clase de sacerdotes "importados" en Judá en el contexto de la ocupación asiria. Otro punto de destaque está en el v. 12, donde se afirma que el rey demolió los altares sobre el terrado del cuarto de Ajaz. Probablemente se trata de una referencia al culto dedicado al ejército de los cielos, cuyos rituales eran practicados en los terrados de Jerusalén. Es importante recordar que Ajaz había sido un vasallo del rey de Asiria, y posiblemente había erguido un lugar de adoración a fin de demostrar su lealtad para con el imperio (cf. 2 Re 16).

Asimismo, la destrucción del símbolo de la diosa Asherá (v. 6) es posible que haya acontecido, especialmente si esta diosa es identificada con la "Reina del Cielo" mencionada en Jr 44. Este texto relata la comprensión de los judaítas que huyeron para Egipto después de la destrucción de Jerusalén. Para ellos, la destrucción ocurrió como venganza de la diosa cuyo culto había sido prohibido. La eliminación de la diosa coincide con la tendencia monolátrica que acompaña a la ideología de centralización del culto ${ }^{15}$.

Por tanto, la reforma histórica de Josías estaba, probablemente, limitada a Jerusalén, a fin de transformar la ciudad en el único lugar legítimo de adoración yavista, y, en consecuencia, YHWH se transformaría en el único Dios a ser adorado. Römer resalta que:

La eliminación de los objetos de culto de inspiración asiria refleja la decadencia de los asirios en el Imperio, lo que permitió a Josías anexar el territorio de Benjamín. Esta incorporación probablemente fue tolerada por primera vez por el rey egipcio, que más tarde, sin embargo, llevó el reinado de Josías a un final abrupto. De acuerdo con el registro bíblico, Josías ascendió al trono a los ocho años de edad (2 Re 22,1). Eso significa que él no gobernó durante los primeros diez años, sino que estaba bajo la custodia de sus consejeros. Los verdaderos autores de la reforma fueron probablemente los dos grupos asociados al oficial de Estado Safán y al sacerdote Jilquías. Esta reforma, de hecho, refleja los intereses de los sacerdotes yavistas, así como de los oficiales del Estado, ambos interesados en la reducción del poder real $^{16}$.

\footnotetext{
14 Römer, “The Rise and Fall of Josiah”, 331-332.

15 Ib., 332.

16 Ib., 333. Traducción nuestra.
} 
Tenemos, por lo tanto, el aspecto histórico y narrativo de la reforma josiánica. Histórico, al apuntar las evidencias de que esta reforma; de hecho, aconteció solo en Jerusalén en búsqueda de la centralización del culto y también en la búsqueda de la independencia del imperio asirio. Narrativo, al discutir las intenciones literarias de los deuteronomistas en legitimar esta violencia con el "libro de la ley", así como apuntar una expansión de esta reforma a Israel Norte, para corroborar la idea de un reino unido presentada por la OHD, y así encerrar la narrativa con la exaltación de la figura del rey Josías, como el rey que se convirtió con todo su corazón y su alma a YHWH (cf. 2 Re 23,25).

\section{2. "Para cumplir la Ley": Consideraciones exegéticas de 2 Reyes 23,1-25}

La reforma josiánica, probablemente, no ocurrió sin violencia. Es más, la narrativa bíblica enfatiza la violencia generada contra las otras deidades y sus respectivos sacerdotes y sacerdotisas. Tal énfasis cumple con su papel narrativo de hacer sobresalir la ideología de los deuteronomistas en las entrelíneas del texto bíblico. La problemática surge cuando utilizamos estos textos para destacar una religión en desprecio de otra. Por eso, analizaremos la narrativa de 2 Re 23,1-25 para discutir la violencia legitimada que se retrata en este relato.

La perícopa en análisis es una continuidad literaria de su capítulo anterior. En cuanto el capítulo 22 tiene como preocupación relatar el hallazgo del libro de la Ley (2 Re 22,3-10) y la búsqueda para conferirle autoridad ( $2 \operatorname{Re} 22,11-20)$, la narrativa 2 Re 23,1-25 es una continuidad de las acciones del capítulo anterior. Ahora, el rey manda llamar a todo el pueblo para leer el libro de la alianza que fue encontrado anteriormente y, a partir de ello, conferirle legitimación divina a su reforma.

Así, la narrativa bíblica de 2 Re 23,1-25 puede ser estructurada de la siguiente forma:

1. Introducción (vv. 1-3)

2. Violencia en Jerusalén y alrededores (vv. 4-14)

3. Violencia en Betel y alrededores (vv. 15-20)

4. Conclusión: Pascua y "reconocimiento" de Josías como mejor rey (vv. 21-25)

La introducción de esta narrativa nos sitúa en el ambiente en que ocurre la legitimación de la reforma de Josías: la lectura del rollo de la ley 
en el Templo de YHWH (v. 2b). A partir de esta lectura, el texto nos informa de que el rey hace la alianza con YHWH a fin de guardar sus mandamientos, testimonios y estatutos con todo su corazón y su alma (v. 3), expresado a través de esta fórmula típicamente deuteronomista. Esta primera escena concluye con la afirmación de que todo el pueblo se unió a la Alianza.

Nos queda una pregunta: ¿Qué libro es este que sirvió de base para legitimar la reforma josiánica? Tradicionalmente, se alude a la lectura de una proto-edición del Deuteronomio, probablemente Dt 6-26 ${ }^{17}$. Sin embargo, este núcleo deuteronómico no fundamenta todas las acciones relatadas en la reforma. De acuerdo con Römer, hay escenas descritas que serían añadidos posteriores ${ }^{18}$. La erradicación del culto a Mólek (v. 10) se basa en prohibiciones de Levítico $(18,21 ; 20,2-5)$, y no en el Deuteronomio. Los teräfim (v. 24) no son mencionados en el Deuteronomio, pero aparecen como “ídolos paganos" en Génesis (31,19.34-35). Además, la expresión "libro de la alianza" aparece en Éxodo $(24,7)$, pero no en Deuteronomio. Eso significa que los capítulos de $2 \mathrm{Re} 22-23$ fueron revisados y ampliados durante los períodos babilónico y persa para transformar el informe sobre la reforma en una historia sobre los orígenes del Pentateuco.

Por lo tanto, el descubrimiento del libro y su lectura pública transforman el topos literario del descubrimiento de la piedra fundamental del templo, que es ampliamente certificado con muchas inscripciones reales asirias y babilónicas. Así, en 2 Re 22, la piedra fundamental es sustituida por el libro, que se convirtió en la "verdadera" fundación del culto yavista. Así, en 2 Re 23, la reforma josiánica pretende transformar el templo en una proto-sinagoga, un lugar donde el libro de la Ley está siendo leído para el pueblo. Römer destaca que esta sustitución del culto sacrificial tradicional por la lectura de la Torá en 2 Re 22-23 constituye una estrategia para subrayar la importancia del rollo escrito ${ }^{19}$. Los editores de la reforma de Josías se preparan para la transformación del judaísmo en una "religión del libro". 2 Re 22-23 en su forma final trata sobre la desaparición del rey en favor del libro.

Es justamente sobre este contexto de la "religión del libro" que debemos analizar críticamente el informe de la reforma josiánica. Toda la violencia allí descrita tiene como fundamento la Ley de la Alianza de YHWH. En nombre de YHWH puede destruirse cualquier tipo de expresión religiosa, e, inclusive matar a los sacerdotes de otras deidades (v. 20).

17 Dietrich, “'Palavra de Deus' e violência”, 179.

18 Römer, "The Rise and Fall of Josiah", 333.

19 Ib., 334. 
Las subunidades que siguen relatan la acción josiánica en Jerusalén y alrededores (vv. 4-14) y Betel y sus alrededores (vv. 15-20). De modo específico, en este análisis nuestro objetivo será evidenciar la violencia relatada a través del lenguaje, especialmente, a partir de los verbos hebreos.

En cuanto a la violencia en Jerusalén y alrededores (vv. 4-14), la primera orden dada a Jilquías y a los sacerdotes de segunda orden fue sacar del templo de YHWH los utensilios hechos para Baal, Asherá y para el ejército de los cielos. Los sacerdotes no solo los sacan, sino que también queman los utensilios y llevan sus cenizas para el torrente del Cedrón (v. 4). No basta solo con retirar los símbolos de otras deidades, es necesario quemarlos, para cumplir lo que ordenaba el rollo de la Ley.

En este sentido, considerando su redacción deuteronomista, existen diversos textos en el Deuteronomio que enfatizan la orden de quemar los símbolos de otros dioses y diosas (cf. Dt 7,5.25; 9,21; 12,3). Es importante resaltar que en todos los textos se usa el verbo śrp "quemar completamente". Cuando este verbo se utiliza en narrativas sobre destrucción de objetos cúlticos de otras divinidades que no sea YHWH, tiene por objetivo simbólico exterminar la deidad al quemar por completo su símbolo ${ }^{20}$.

Además, este verbo aparece frecuentemente en esta narrativa. En el v. 6 se utiliza para hablar de la quema de Asherá; en el v. 11 quema los carruajes de Shemesh; en el v. 15 quema los lugares altos en Betel y, nuevamente, Asherá; en el v. 16 quema los huesos de los sepulcros; en el v. 20 quema los huesos de los sacerdotes que fueron inmolados sobre el altar de los lugares altos. Esta reincidencia cumple con el objetivo de exterminar cualquier pluralidad cúltica en Judá y, narrativamente, en Israel Norte, cumpliendo con el propósito deuteronomista de un solo Dios, un solo pueblo y un solo templo.

El v. 5 inicia así el relato: "e hizo cesar a los sacerdotes que pusieron los reyes de Judá, que quemaban incienso en los lugares altos" 21 . Optamos traducir el verbo šbt por "hacer cesar" en lugar de "remover", puesto que este verbo, en el antiguo Israel, era utilizado con el sentido de hacer cesar el trabajo para el día de descanso ${ }^{22}$. Es más, es la misma raíz para el sustantivo šabbātôn. Por lo tanto, el texto indica la conclusión del trabajo de estos sacerdotes.

Es importante evidenciar esta cuestión verbal para así destacar la pluralidad religiosa que había también en Jerusalén y no solamente en los

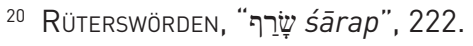

21 Traducción nuestra.

22 HAA, “草 šabbāt", 388. 
cultos domésticos y en los santuarios regionales. Aún más cuando existe una tendencia a ver la religión estatal como algo exclusivamente yavista, durante todo el período monárquico. Sin embargo, los libros de los Reyes revelan esa dinámica entre la fe exclusiva de YHWH y la pluralidad religiosa popular de la vida familiar del pueblo israelita en la esfera estatal. Las reformas de Ezequías (2 Re 18,3-4) y Josías (2 Re 23,4-14), así como diversos relatos de reyes que introdujeron la diosa Asherá y otra deidad en el templo, por ejemplo Manasés (2 Re 21,3-7), indican la presencia de diversas divinidades. Entretanto, el juicio deuteronomista es enfático al juzgar como impíos y repulsivos a quienes sirven a la diosa o a otros dioses ${ }^{23}$.

Otro verbo recurrente en esta narrativa es $n t s$ "demoler". Este verbo se refiere a una violenta derrumbada de casas, torres, muros, ciudades enteras, como también altares, santuarios en los lugares altos y otras instituciones cúlticas. Cuando es usado en la forma Qal, el verbo busca enfatizar la acción en sí, y cuando se encuentra en Piel, el verbo trae el énfasis para el resultado final de la acción. Su mayor ocurrencia está en los relatos de destrucción de los santuarios no yavistas -e incluso no exclusivamente yavistas- y objetos cúlticos, o sea, en los relatos de reforma cúltica, sea la de Josías, como tambiéen la relatada en Jue 6,48 hecha por Gedeón, e incluso la destrucción de Asherá por Asá (cf. 1 Re 15,12) ${ }^{24}$.

En la narrativa de $2 \operatorname{Re} 23,1-25$ el verbo aparece solo en su forma Qal, indicando, por tanto, que el énfasis de la narrativa está en retratar la acción violenta realizada por los sacerdotes para demoler la casa de los sagrados (v. 6); demoler los lugares altos (vv. 8.12.15). De esta demolición, en Jerusalén y alrededores, solo existen relatos de destrucción. Ya en Betel, es necesario "quemar completamente" los restos de esta demolición (vv. 15): "Y también el altar que [estaba] en Betel, el lugar elevado que hizo Jeroboán, el hijo de Nebat que hizo transgredir a Israel, también aquel altar, y el lugar elevado demolió y quemó el lugar elevado; molió como polvo y quemó Asherá” 25 .

A partir del v. 15, entonces, se tiene el relato de la supuesta reforma de Josías en Israel Norte. Supuesta, porque como ya discutimos, no hay evidencias arqueológicas para tal destrucción. Sin embargo, podemos analizarla narrativamente, considerando las adiciones posteriores a este texto de $2 \operatorname{Re} 23,1-25$.

\footnotetext{
23 Matos, As sagradas de Asherah, 354.

24 BARTH, "נָָָּ nātas", 109-110.

25 Traducción nuestra.
} 
El inicio de esta subunidad (v. 15) tiene por objetivo exaltar la figura de Josías como aquel que realmente puso fin al "pecado de Jeroboán", acusado de haber construido los santuarios yavistas del norte en Betel y Dan. Diferente de la subunidad anterior, que relata diversas divinidades presentes en Jerusalén, esta subunidad solo menciona la destrucción de los altares y de los lugares altos. La única divinidad que fue molida y quemada fue Asherá. Es más, repetidamente ella aparece en toda la narrativa como deidad que debe ser destruida. Todo este esfuerzo para apagar el culto a la diosa solo evidencia cuán popular era en medio de los israelitas y judaítas. Inclusive hay una reclamación en Jr 44,15-19 sobre la abundancia que había cuando ofrecían libaciones y quemaban incienso a la Reina del cielo ${ }^{26}$, lo que también demuestra que esta reforma no fue bien recibida por el pueblo.

Los versículos 16-18 se remontan a la historia del hombre de Dios de Judá que anunció la profanación y la destrucción del altar por parte de Josías (cf. 1 Re 13,2-3) y que fue sepultado junto con un profeta de Betel (1 Re 13,30). El redactor que añadió 2 Re 23,15-18 enfatizó el hecho de que Josías, al destruir el altar de Betel, estaba cumpliendo la profecía de $1 \operatorname{Re} 13^{27}$.

Se nota que la reforma implementada en Israel Norte fue realizada por las manos de Josías, mientras que en Jerusalén es ordenada al sacerdote Jilquías y a los sacerdotes de segundo orden. El énfasis, por lo tanto, es distinto. Mientras en Judá la reforma realizada por los sacerdotes busca legitimar el Templo y, por consiguiente, el sacerdocio yavista, la reforma realizada en Israel Norte tiene como objetivo destacar la figura mesiánica de Josías sobre todo el reino.

El versículo 19, a su vez, puede ser una adición posterior destinada a sugerir que Josías no destruyó Betel, sino todos los altos de Samaría. Este pasaje es probablemente una polémica anti-samaritana judaíta, y puede reflejar la hostilidad de Judá para con el antiguo Reino del Norte, en una tendencia similar a $2 \operatorname{Re} 17,24-41^{28}$.

La reforma en el Norte, entonces, concluye con el sacrificio de los sacerdotes de los lugares altos, y quemó completamente los huesos humanos sobre los altares (v. 20), finalizando lo que había sido "profetizado" en 1 Re 13,2. Ante este Dios de la Ley, propuesto por los deuteronomistas en la narrativa de 2 Re 23,1-5, no hay sobrevivencia para aquel que no sirva a YHWH.

26 Probablemente esta Reina del Cielo se refiere a Asherá, y no a Ishtar, aunque sea posible considerar alguna asimilación de las características de la diosa asiria por Asherá.

27 RÖMER, 330.

28 Ib., 330. 
De este modo, nos genera una cuestión importante para nuestra hermenéutica al discutir la problemática de la intolerancia religiosa en los días actuales. Respaldado por la "Palabra de Dios" y usando Josías como ejemplo, se destruye y se demoniza la religión del otro. Es más, la narrativa bíblica así lo coloca. Después de celebrar la pascua, Josías es ahora presentado por los narradores como aquel que retornó con todo corazón, con toda alma, y con toda fuerza a la Ley de Moisés, y después de él no hubo otro rey que fuera igual.

\section{Sacerdotes, mujeres, dioses y diosas: la relación de poder entre los sexos}

Analizar la narrativa de 2 Re 23,1-25 a partir de la perspectiva de género es un gran desafío. Existen diversos presupuestos teóricos para tal discusión. Haremos el recorte a partir del presupuesto que discutir género es discutir la relación de poder entre los sexos. De acuerdo con Scott,

[...] género es un elemento constitutivo de las relaciones sociales con base en las diferencias percibidas entre los sexos; y el género es una forma primera de significar las relaciones de poder. Los cambios en la organización de las relaciones sociales corresponden siempre al cambio en las representaciones de poder, pero la dirección del cambio no sigue necesariamente un sentido único ${ }^{29}$.

Según la autora ${ }^{30}$, el género, como elemento constitutivo de las relaciones sociales fundadas sobre diferencias percibidas entre los sexos, implica cuatro elementos relacionados entre sí: símbolo de la mujer, conceptos normativos, sistema de parentesco e identidad subjetiva. Entre estos elementos es importante resaltar que los conceptos normativos colocan en evidencia interpretaciones del sentido de los símbolos que intentan limitar y contener sus posibilidades metafóricas. O sea, son los conceptos normativos que van a servir de clave hermenéutica para comprender el símbolo de la mujer, y también del hombre.

Tales definiciones son fundamentales para que analicemos las relaciones de poder que envuelven los/las personajes de la narrativa de 2 Re 23,1-25. En una lectura atenta de esta narrativa bíblica observamos las diferencias de las relaciones entre masculino y femenino, sean divinidades o seres humanos.

Las acciones promovidas contra los sacerdotes de otras divinidades se diferencian desde el punto de vista territorial (Judá y Betel/Samaría). A

29 Scott, Gênero, 21.

30 lb., 21. 
los sacerdotes de otras divinidades de Jerusalén y alrededores, el texto nos informa de que los sacerdotes de Josías hicieron cesar $(\breve{s} b t)$ sus actividades (v. 5), y también profanaron los altares (vv. 8.10). La relación de poder, aquí explicitada, no está vinculada a las diferencias entre los sexos, sino a la diferencia religiosa. La violencia legitimada excluye y profana los altares donde estos sacerdotes realizaban sus ofrendas. Mientras los sacerdotes de Israel Norte son inmolados (v. 20) por el propio Josías, de acuerdo con la narrativa, para reforzar la concepción de Israel Norte como un territorio idolátrico y, así, prevalecer la ideología yavista judaíta de los deuteronomistas.

Asimismo, cuando la narrativa menciona la demolición de la casa de los sagrados (v. 7), observamos que las categorías se interrelacionan, puesto que los sagrados $\left(q^{e}\right.$ déšîm $)$ mencionados en el texto serían hombres al servicio de la diosa Asherá ${ }^{31}$. La presencia de este grupo ya había sido descrita desde los tiempos de Roboán (siglo x A. E. C.), pero de manera negativa, como aquellos que "actuaron según todas las cosas abominables de las naciones que expulsara delante de los hijos de Israel" (1 Re 14,24).

Además, ellos no están solos, pues también aparece la mención a las mujeres que allí estaban tejiendo vestidos para la diosa Asherá. De acuerdo con Römer ${ }^{32}$, estos sagrados podrían ser relacionados con los travestis ${ }^{33} \mathrm{o}$ eunucos al servicio de la diosa Ishtar, de quien Asherá sería su equivalente en Judá. La prohibición del travesti por el Deuteronomio (Dt 22,5) comprueba esta hipótesis. Por lo tanto, resaltar esta intersección es fundamental para aclarar que el culto a la diosa nunca fue exclusividad femenina, sino familiar, ya que una de las funciones primordiales de la diosa era la vida.

En este mismo versículo (v. 7) el texto nos presenta una forma de violencia contra las mujeres que servían a Asherá. De forma diferente a los sagrados y a los sacerdotes, las mujeres que allí servían a la diosa no son nombradas con sus funciones cúlticas, que serían las sagradas $\left(q^{e} d \bar{e} s ̌ o ̈ t\right)$. Intencionalmente, se trata de una forma de invisibilizarlas y descaracterizarlas, por parte de los historiadores deuteronomistas, puesto que, de acuerdo con Scott, "no se puede garantizar la neutralidad del historiador, pues decidir qué categorías se deben historicizar es inevitablemente una acción

31 Trabajamos el concepto de $q^{e}$ dēšîm y q $q^{e}$ ēšot como personas consagradas al servicio de una divinidad, para así evitar cualquier connotación equivocada con el término "prostituta/o", una vez que los términos hebreos denotan la separación de una persona para el servicio de una divinidad, aunque este servicio incluya la práctica de sexo en sus rituales, pues para ellas/os el sexo formaba parte del ritual de servicio a la diosa Asherá.

32 Römer, A origem de Javé, 194-195.

33 Término utilizado por el propio autor. 
política, está necesariamente vinculada al reconocimiento del lugar del historiador en la producción del conocimiento" ${ }^{34}$.

De esta manera, entendiendo que los deuteronomistas se comprometen a escribir la historia de Israel y Judá, aplicamos el concepto propuesto por Scott, en la medida en que los deuteronomistas tienen su propia ideología de centralización del culto y, en consecuencia, centralización del poder. Por lo tanto, no son escritores neutrales de la historia de Israel y Judá.

Los deuteronomistas, cuando no las invisibilizan, como en este texto de 2 Re 23, les atribuyen símbolos peyorativos. Por ejemplo, en Dt 23,1819 equipara la sagrada $\left(q^{e} d \bar{e} s ̌ \bar{a} h\right)$ con la prostituta (zōnāh). Por tanto, la mujer que no se encuentra dentro de la estructura normativa yavista es descalificada. Esto queda bien claro cuando Asá depuso a su madre del estatus de reina-madre por haber construido una imagen de Asherá que, según la narrativa, era "una imagen abominable" (cf. 1 Re 15,13).

En resumen, servir a la diosa, tanto para los hombres como para las mujeres, en la perspectiva deuteronomista, es "abominación". Esto nos lleva a otro punto relevante de la discusión de la violencia relatada en 2 Re 23,1-25: la violencia contra Asherá. En una lectura atenta de la narrativa bíblica observamos que la violencia que recae sobre la diosa Asherá es nítida y enfática, mucho más que sobre las otras divinidades.

En cuanto las otras divinidades son retiradas y quemadas, Asherá debe ser quemada y pulverizada (cf. v. 6). El uso del verbo śrp "quemar completamente" ya denota la violencia simbólica contra las divinidades al quemar sus símbolos y sus representaciones. Sin embargo, al referirse a Asherá, no solo la quemaron completamente, sino que también la "pulverizaron" $(d q q)$. Para imponer la monolatría yavista, el culto a la diosa debe ser exterminado de la forma más violenta posible, sin duda porque el culto a la diosa era popular $^{35}$, además de haber recibido culto como consorte de YHWH, como nos indican las inscripciones de Kuntilet 'Arjud ${ }^{36}$, por ejemplo:

Dice [...] Diga a Jehallel [...] Josafá y [...]: Los bendigo en YHWH de Samaría y su Asherá.

Dice Amarjahu: Diga a mi señor: ¿Estás bien? Te bendigo en YнwH de Teman y su Asherá. Él te bendiga y te guarde y con mi señor ${ }^{37}$.

34 ScotT, 325.

35 Existen diversas evidencias arqueológicas que comprueban tal afirmación. Cf. Matos, "As sagradas de Asherah".

${ }^{36}$ En Kuntillet 'Ajrud fueron descubiertas inscripciones en dos jarras fechadas en el s. vIII A. E. C.

37 Cordeiro, Onde estão as Deusas?, 39. 
Además, la prohibición de Dt 16,21-22 de establecer una Asherá junto al altar de YHWH remite a este culto a la pareja YHWH y Asherá, solo que en la perspectiva deuteronomista esto está prohibido porque "YHWH, tu Dios, lo detesta" (v. 22). En este texto, así como en otros, la figura de la diosa Asherá es siempre tratada con odio, abominación y violencia.

En este intento por extinguir el culto a la diosa, tenemos también la violencia simbólica al masculinizar su símbolo. En el v. 14 se mencionan los símbolos de la diosa en su forma masculina plural 'ašérîm, siendo lo correcto, por la gramática hebrea, 'ašêrôt, plural femenino. Otros textos bíblicos también traen su símbolo en masculino plural (cf. 1 Re 14,23; 2 Re 17,10; 2 Cr 14,2; 17,6; 24,18; 31,1; 33,19; 34,3-4.7; Is 17,8; 27,9) indicando un intento de apagar cualquier memoria de la diosa ${ }^{38}$. Se nota que la mayoría de estos textos es tardía, retratando el monoteísmo masculino del post-exilio.

A pesar del intento de los redactores bíblicos por hacer olvidar a la diosa, especialmente con la destrucción por la reforma josiánica, su culto continuó en Israel y Judá, por lo menos hasta el período persa. Existen indicios arqueológicos que comprueban el culto a la diosa. En Samaría fueron encontradas monedas fechadas en el período persa, con el dibujo de dos mujeres, donde una le entrega una especie de torta a la otra, simbolizando la ofrenda de una sacerdotisa a la diosa ${ }^{39}$.

El texto bíblico de Zc 5,5-11, escrito alrededor del siglo v A. E. C., retrata la prohibición del culto a la diosa Asherá. La diosa, entonces, transformada en iniquidad, es llevada para Sennar, por dos mujeres con alas. Ribeiro propone que estas mujeres con alas serían:

[...] representaciones graciosas del cuerpo sacerdotal -femenino- del culto están presentes en la "visión". Así, las mujeres con alas podrían significar una representación jocosa -por ser descritas en la forma de demonios babilónicos del desierto- de las portadoras del culto a la diosa, profetisas/ sacerdotisas, ahora también expulsadas de Jerusalén ${ }^{40}$.

Mucho más que evidenciar la continuidad cúltica, este texto de Zacarías refuerza la violencia simbólica contra la diosa y sus sacerdotisas, a punto de ser transformadas en iniquidad (diosa) y representadas como demonios del desierto (sacerdotisas). Y, nuevamente, lo femenino es simbolizado negativamente. Los conceptos normativos de la sociedad teocrática

$38 \mathrm{lb} ., 44$.

39 LEITH, Religious Continuity, 267-304.

40 Ribeiro, A deusa do efa, 203-204. 
yavista del post-exilio hacen que el sagrado masculino se establezca en el poder, y así el sagrado femenino debe ser retirado de Jerusalén.

Sin embargo, a pesar de la violencia y los mecanismos de olvido, la memoria de la diosa permanece en las apropiaciones de atributos, títulos y funciones por parte de la divinidad de $\mathrm{YHWH}^{41}$, una forma en que algunos escritores y, por qué no, escritoras, encontraron de resistir a la dominación de la divinidad masculina.

\section{Consideraciones finales}

La discusión presentada sobre narrativa, arqueología e historia de la reforma de Josías nos permitió elaborar el marco político-teológico en el que se encuentra la narrativa de 2 Re 23,1-25. Es un período en el que Judá tiene cierta autonomía política debido a la decadencia del imperio asirio, y, en consecuencia, comienza el proyecto de la institución de la monolatría en Judá, centralizando el culto en Jerusalén, así como el poder monárquico y sacerdotal. Con base en ello, en la segunda sesión, elaboramos la discusión sobre los aspectos exegéticos de la narrativa de 2 Re 23,1-15, destacando los diferentes tipos de violencia legitimada "para cumplir con la ley".

Así, considerando la discusión presentada en este artículo, junto con el presupuesto de que la violencia simbólica es aquella que conduce el dominado a incorporar clasificaciones naturalizadas ${ }^{42}$, observamos que la narrativa de 2 Re 23,1-25 refuerza esta violencia, principalmente cuando se enmarca el texto dentro de la tradición de "Palabra de Dios". Además, desde esta perspectiva, el texto fomenta la intolerancia religiosa, así como refuerza las estructuras patriarcales con relación a lo femenino, especialmente al sagrado femenino.

La problemática de la supresión de una divinidad femenina se refleja en la comprensión de los cuerpos femeninos en la religión, pues:

Con relación a la divinidad, el vacío femenino está presente en los cielos. Las mujeres nunca fueron dignas de estar sentadas en el cielo, ni tener ángeles a sus pies. Las mujeres nunca tuvieron verdaderamente su "equivalente" divino en los cielos. Tuvieron que contentarse con el rostro de la divinidad masculina, forzosamente convencidas de su inferioridad ontológica e histó-

41 Para este asunto, véase Matos, “A influência”, 1-20.

42 Bourdieu, A Dominação Masculina, 47. 
rica, pues nada en ellas se asemejaba a lo divino para merecer una habitación digna en los cielos ${ }^{43}$.

Las mujeres, históricamente convencidas de su inferioridad, como afirma la autora, consecuentemente son invisibilizadas. Ellas son las sujetas ocultas de la historia de la Iglesia cristiana. Cargan la "Iglesia en sus espaldas", pero no son visibilizadas, así como las mujeres que tejían vestidos para Asherá. Nuestro desafío hermenéutico, por lo tanto, está justamente en visibilizarlas, sean ellas las sagradas de Asherá o las "Marías" de las comunidades eclesiásticas. Por lo tanto, rescatar la imagen de lo divino femenino, de la diosa, posibilita nuevos caminos hermenéuticos para transgredir los conceptos normativos religiosos y romper con la violencia legitimada por la "Palabra de Dios".

\section{Bibliografia}

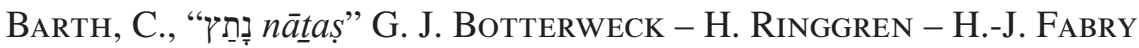
(eds.), Theological Dictionary of the Old Testament, X, Grand Rapids 1999, 108-114.

Bourdieu, P., A Dominação Masculina, Rio de Janeiro 1999.

Cordeiro, A. L. A., Onde estão as Deusas? Asherah, a Deusa proibida, nas linhas e entrelinhas da Bíblia, São Leopoldo 2011.

Dietrich, L. J., "Palavra de Deus" e violência. A urgência de uma leitura descolonizadora da Bíblia. In: UNITAS - Revista Eletrônica de Teologia e Ciências das Religiões, Vitória-ES, v. 6, n.1, jan.-ago., 2018, 174-192, disponible en: http://revista.faculdadeunida.com.br/index.php/unitas/article/view/770 [consulta: 17/04/2019].

Finkelstein, I. - MaZAR, A., The Quest for the Historical Israel: Debating Archaeology and the History of Early Israel, Atlanta 2007.

Finkelstein, I. - Singer-Avitz, L., "Reevaluating Bethel", ZDPV 125 (2009) 33-48.

Gebara, I., Conhece-te a ti mesma: Uma leitura feminista do humano, São Paulo 1991.

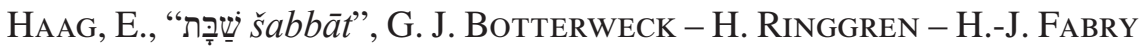
(eds.), Theological Dictionary of the Old Testament, XIV, Grand Rapids 2004, 387-397.

43 Gebara, Conhece-te a ti mesma, 18. 
IsRaEL, D., "Seal Bearing Name of King Josiah's Court Official Uncovered in City of David", The Jewish Press, 24 Adar II 5779 - 31 de marzo de 2019, disponible en: https://www.jewishpress.com/news/israel/jerusalem/ seal-bearing-name-of-king-josiahs-court-official-uncovered-in-city-ofdavid/2019/03/31/ [consulta: 01/05/2019].

LeITH, M. J. W., "Religious Continuity in Israel/Samaria: Numismatic Evidence", en Ch. Frevel - K. Pyschny - I. Cornelius (eds.), A “religious Revolution" in Yehûd? The Material Culture of the Persian Period as a Test Case (OBO 267), Fribourg 2014, 267-304.

Liverani, M., Para Além da Bíblia: História Antiga de Israel, São Paulo 2008.

Matos, S.'H. Monteiro de, "A influência das Deusas Asherah e Ishtar na construção da imagem materna de Javé em Dêutero-Isaías", Âncora 9 (2014) 1-20, disponible en: http://www.revistaancora.com.br/.

-, "As sagradas de Asherah: culto à Deusa no antigo Israel", Caminhos 17 (2019) 352-370, disponible en: http://seer.pucgoias.edu.br/index.php/ caminhos/article/view/7000 [consulta: 02/01/2019].

Ribeiro, O. L., "A deusa do efa: hipótese de interdição ao culto de Asherah em Zc 5,5-11", Revista Pistis Praxis 6.1 (2014) 191-208, disponible en: https://periodicos.pucpr.br/index.php/pistispraxis/article/view/ 13076/12503 [consulta: 07/05/2019].

RöMER, Th., A chamada história deuteronomista: Introdução sociológica, histórica e literária, Petrópolis 2008.

-, A origem de Javé: o Deus de Israel e seu nome, São Paulo 2016.

-, "The Rise and Fall of Josiah", en O. LiPSCHITS - Y. GADOT - M. J. AdAMS (eds.), Rethinking Israel: Studies in the history and archaeology of Ancient Israel in honor of Israel Finkelstein, Winona Lake 2017.

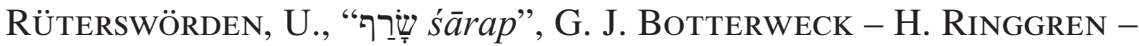
H.-J. FABRY (EDS.), Theological Dictionary of the Old Testament, XIV, Grand Rapids 2004, 218-228.

Schmidt, W. H., Introdução ao Antigo Testamento, São Leopoldo ${ }^{4} 2009$.

Scotт, J. W., "Gênero: uma categoria útil de análise histórica", Educação e Realidade 16.2 (1990) 5-22, disponible en: http://seer.ufrgs.br/index. php/educacaoerealidade/article/view/71721 [consulta: 03/05/ 2019].

-, "A invisibilidade da experiência", Projeto História 16 (1998) 297-325, disponible en: https://revistas.pucsp.br/index.php/revph/article/download/11183/8194 [consulta: 07/05/2019].

[recibido: 24/10/19 - aceptado: 30/01/20] 